\title{
BENCHMARKING OF FREE AUTHORING TOOLS FOR MULTIMEDIA COURSES DEVELOPMENT
}

\author{
Peter KOŠČ $\check{C}^{*}$, Mária GAMCOVÁ ${ }^{* *}$, Ján ŠTEC, Dušan KOCUR ${ }^{* *}$ \\ *Department of Electrotechnics and Mechatronics, Faculty of Electrical Engineering and Informatics, Technical University of \\ Košice, Letná 9, 04200 Košice, Slovak Republic, e-mail: peter.kosc@tuke.sk \\ ${ }^{* *}$ Department of Electronics and Multimedia Communications, Faculty of Electrical Engineering and Informatics, \\ Technical University of Košice, Letná 9, 04200 Košice, Slovak Republic, e-mail: maria.gamcova@tuke.sk, dusan.kocur@tuke.sk
}

\begin{abstract}
In this article, four free authoring tools have been selected. Following, the selected tools using benchmarking method have been compared. The benchmarking purpose is to show advantages and disadvantages of selected authoring tools and to provide recommendations for users with small experiences in multimedia technologies.
\end{abstract}

Keywords: e-learning, authoring tool, benchmarking, e-learning standards

\section{INTRODUCTION}

For multimedia courses development authoring tools are usually used. These tools have ability to combine texts with multimedia like animations, video or audio recordings, but interactive tasks and tests as well. Authoring tool is a software application for development of multimedia content usually published on Internet. Multimedia courses are published on Internet within Learning Management Systems (LMS) or distributed offline on CDs.

Simple authoring tools are based on templates, that are easy to use but flexibility is small. The course development is managed by a sequence of dialog windows. On the other hand, much sophisticated authoring tools are designed for production of advanced multimedia animations. These tools usually require experienced specialists and offer higher freedom of creativity [1].

It is obvious, that text-based study material does not fulfil present requirements. Following, it is important to have the tools that enable us to insert pictures, interactive animations, audio or video recordings. In some cases, a video recording provides better explanation than verbal description. Ability to import documents in various formats is important as well. Authoring tools should provide functionality of automatic knowledge testing with basic tasks like simple choice, multi choice, filling or assigning exercises. Appropriate templates in professional design should be also delivered [10], [11].

For authoring tools a support of e-learning standards and specifications is important requirement [2], [3], [4]. The standards provide a content re-usability for different Learning Management Systems. Besides the standards support multimedia course should be possible to export as a publication for web or as offline CD material.

\section{SELECTION OF AUTHORING TOOLS}

One of important criteria during selection of appropriate authoring tool in case of educational institutions is an intuitive development process and financial aspects. Some open-source or free tools fulfil both requirements and touch many commercial tools for functionality. On the other hand, free authoring tools usually do not reach a quality of advanced commercial tools, that are able to produce complex multimedia animations and are used by professionals. In next paragraphs, we will briefly characterize selected free authoring tools that are suitable for multimedia course development in educational institutions.

Authoring tool Microsoft Learning Content Development System (LCDS) is freely available and offers user-friendly production of multimedia courses including professional design and support for various interactive components. This tool provides about 20 templates that simplify a course development. Disadvantage could be limited text formatting options due to restricted editor functionality. Developed courses are fully compatible with only Microsoft Internet Explorer, moreover, a final course design is not possible to edit. Courses can be published as web pages, as Word documents or using the standard packages SCORM 1.2. Results of tests can be traced online using server connection [5].

Next authoring tool is CourseLab developed by Russian company WebSoft Ltd. The tool is available for free only in version 2.4 from year 2009. It offers advanced user environment and well supported standards. Course development is object-oriented with possibility of complex animations and scenarios. Another advantage is a rich text editor and media support in different formats. Development of test supports several types of questions and tasks. Final course is possible to publish as web pages or using the standard packages AICC, SCORM 1.2 and SCORM 2004. Limitation could be course optimization for only two web browsers, Internet Explorer and Mozilla Firefox, but next commercial version 2.7 will support all web browsers [6].

Open-source software eLearning XHTML Editor $(\mathrm{eXe})$ is the authoring tool with intuitive and user-friendly environment. Advantage is a rich-text editor, multimedia support of various formats and course optimization for all web browsers. Possibility to insert the mathematical formulas using integrated LaTeX editor could be an interesting option for production of technically aimed study materials. Disadvantage is a quite unprofessional course design. On the other hand, it can be improved by 
technically experienced users. Another limitation is a poor support of interactivity and scenarios. Course distribution is possible using the standards IMS Content Package, SCORM 1.2 or simply by web pages [7].

Quite interesting authoring tool is web application myUdutu.com that allows free and online development of multimedia courses using Udutu.com servers. This online tool offers a quite large number of intuitive templates that allow technically less experienced authors to develop various types of multimedia content including interactive scenarios and tests. Advantage is a rich-text editor, online images optimization for web, online video converting to flash format and professional course design with editing possibility. Unlike other authoring tools, it is possible to import PowerPoint presentations and pdf documents. Important feature is a course optimization for all web browsers. Developed courses can be published on Udutu servers as paid hosting service. Second possibility is a free course download as web pages packaged in zip format or as the standard packages SCORM 1.2 and SCORM 2004. Advantage to use a web application as authoring tool is accessibility of Internet without limits to one computer or operating system and ability to support teamwork during course development. On the other hand, disadvantage could be requirement of Internet connection, possible server latency and risk of cancelling service [8].

\section{BENCHMARKING OF AUTHORING TOOLS}

The authoring tools mentioned in previous paragraphs were tested in version Microsoft LCDS 2.6, eXe 1.04, CourseLab 2.4 and myUdutu.com from May 2011. Following, ten basic requirements for authoring tools were selected, in particular, four technical and six functional requirements. Moreover, each requirement was weighted to receive more correct benchmarking results. Technical requirements are support of software platforms, export of course content, support of e-learning standards and optimization for different web browsers. Functional requirements include course design and documents import, text editing, multimedia support, tests and exercises, interactive components and scenarios, and another specific functionality [9].

Mentioned requirements emerge from assumption that benchmarking are designed for users without any advanced technical experiences in multimedia and web technology. From this reason there was not set any individual requirement for development of complex multimedia animations that usually require an experienced team of professionals.

First technical requirement is a possibility to use authoring tool in various software platforms that could be important issue for some users (Tab. 1). Regarding to worldwide use of Microsoft platform, each tool gained two points for Windows support, other platforms gained 0.5 points.

Important technical requirement is an export of developed multimedia course into formats that provide different options for course distribution (Tab. 2). Course usability within various LMS is ensured by export in elearning standard packages. In some cases, it is enough to have available course web pages that can be distributed online on Internet or offline on CDs. Good option for students can be possibility of course export as a set of documents available for printing and study without computer. Each authoring tool gained one point for support of e-learning standards or web pages. On the other hand, documents support gained 0.5 points.

Table 1 Support of software platforms

\begin{tabular}{|c|c|c|c|c|}
\hline & CourseLab & eXe & myUdutu & LCDS \\
\hline Windows & $\bullet$ & $\bullet$ & $\bullet$ & $\bullet$ \\
\hline Linux & & $\bullet$ & $\bullet$ & \\
\hline Mac OS X & & $\bullet$ & $\bullet$ & \\
\hline \hline Points & 2 & 3 & 3 & 2 \\
\hline
\end{tabular}

Table 2 Export of course content

\begin{tabular}{|c|c|c|c|c|}
\hline & CourseLab & eXe & myUdutu & LCDS \\
\hline $\begin{array}{c}\text { E-learning } \\
\text { standards }\end{array}$ & $\bullet$ & $\bullet$ & $\bullet$ & $\bullet$ \\
\hline Web pages & $\bullet$ & $\bullet$ & $\bullet$ & $\bullet$ \\
\hline Documents & & & & $\bullet$ \\
\hline Points & 2 & 2 & 2 & 2.5 \\
\hline
\end{tabular}

More supported e-learning standards and specifications mean better compatibility with different LMS and more opportunities for students as well (Tab. 3). To compare authoring tools, following standards and specifications were selected: the standard AICC as one of the first e-learning standards, the specification IMS Content Package, the reference model SCORM in versions 1.2 and 2004. Each authoring tool gained one point for support of standards AICC or SCORM, support of IMS specification gained 0.5 points.

Table 3 Support of e-learning standards

\begin{tabular}{|c|c|c|c|c|}
\hline & CourseLab & eXe & myUdutu & LCDS \\
\hline AICC & $\bullet$ & & & \\
\hline IMS & & $\bullet$ & & \\
\hline $\begin{array}{c}\text { SCORM } \\
1.2\end{array}$ & $\bullet$ & $\bullet$ & $\bullet$ & $\bullet$ \\
\hline $\begin{array}{c}\text { SCORM } \\
2004\end{array}$ & $\bullet$ & & $\bullet$ & \\
\hline \hline Points & 3 & 1.5 & 2 & 1 \\
\hline
\end{tabular}

Last technical requirement is a course optimization for various web browsers that is especially important in cases, where study materials are available for public on web portals (Tab. 4). On the other hand, in case of private study groups, e.g., within University LMS, it is acceptable to require from students specific web browser. Five most frequently used browsers were tested in versions: Google Chrome 10.0, Mozilla Firefox 4.0, MS Internet Explorer 7/8/9, Opera 11.10 and Safari 5.0.4.

First functional requirement is a course design and possibility to import already prepared documents, mainly in formats pdf and ppt (Tab. 5). Professional design is important issue for overall course success. The tools 
CourseLab and myUdutu have available user-friendly environment for editing final course design. In case of LCDS tool, users have to be satisfied with only one version of professional design. Authoring tool eXe provides quite amateurish course design. On the other hand, technically skilled users are able to overcome this drawback by editing html/css code.

Table 4 Optimization for web browsers

\begin{tabular}{|c|c|c|c|c|}
\hline & CourseLab & eXe & myUdutu & LCDS \\
\hline Chrome & & $\bullet$ & $\bullet$ & \\
\hline Firefox & $\bullet$ & $\bullet$ & $\bullet$ & \\
\hline Explorer & $\bullet$ & $\bullet$ & $\bullet$ & $\bullet$ \\
\hline Opera & & $\bullet$ & $\bullet$ & \\
\hline Safari & & $\bullet$ & $\bullet$ & \\
\hline \hline Points & 2 & 5 & 5 & 1 \\
\hline
\end{tabular}

Import of prepared documents into multimedia course is a weak point of selected authoring tools. Only on-line tool myUdutu offers free documents import in Adobe pdf format and PowerPoint ppt format as well. In case of CourseLab tool, it is possible to buy optional plug-in for PowerPoint import. It is necessary to mention, that all tools are able to link uploaded documents. Each authoring tool gained one point for support of particular functionality [10].

Table 5 Course design and documents import

\begin{tabular}{|c|c|c|c|c|}
\hline & CourseLab & eXe & myUdutu & LCDS \\
\hline $\begin{array}{c}\text { Professional } \\
\text { course design }\end{array}$ & $\bullet$ & & $\bullet$ & $\bullet$ \\
\hline $\begin{array}{c}\text { Editing of } \\
\text { course design }\end{array}$ & $\bullet$ & & $\bullet$ & \\
\hline Import ppt & & & $\bullet$ & \\
\hline Import pdf & & & $\bullet$ & \\
\hline \hline Points & 2 & 0 & 4 & 1 \\
\hline
\end{tabular}

Second functional requirement is a text editing. Basic functions including hypertext links fulfil all tools (Tab. 6). So called rich text editor provides better text editing, e.g., tables creating, images inserting, etc. In case of LCDS tool, advanced text editing is solved by various templates that simplify course development but lower flexibility. On-line tool myUdutu offers a variety of templates and a rich text editor as well. Inserting of mathematical formulas is possible only in tool eXe using integrated LaTeX editor. Each authoring tool gained one point for support of mentioned functionality.

Next functional requirement is a multimedia support (Tab. 7). Mainly web formats are supported, it means $\mathrm{jpg} / \mathrm{png} / \mathrm{gif}$ for images, mp3 for audio, swf flash for video and animations. The tools CourseLab and eXe provide support of Java applets as well, that can be useful for authors looking for free educational animations available on Internet. Web application myUdutu supports online conversion of images and video files to appropriate web formats. Media players provided by authoring tools have usually limited functionality, but technically skilled users can replace them by free media players (e.g., JWplayer) offering additional features as advanced sound control, video enlargement, etc.

Table 6 Text editing

\begin{tabular}{|c|c|c|c|c|}
\hline & CourseLab & eXe & myUdutu & LCDS \\
\hline $\begin{array}{c}\text { Basic } \\
\text { editing }\end{array}$ & $\bullet$ & $\bullet$ & $\bullet$ & $\bullet$ \\
\hline $\begin{array}{c}\text { Advanced } \\
\text { templates }\end{array}$ & & $\bullet$ & $\bullet$ & $\bullet$ \\
\hline $\begin{array}{c}\text { Rich Text } \\
\text { Editor }\end{array}$ & $\bullet$ & $\bullet$ & $\bullet$ & \\
\hline $\begin{array}{c}\text { Equation } \\
\text { inserting }\end{array}$ & & $\bullet$ & & \\
\hline \hline Points & 2 & 3 & 3 & 2 \\
\hline
\end{tabular}

Table 7 Multimedia support

\begin{tabular}{|c|c|c|c|c|}
\hline & CourseLab & eXe & myUdutu & LCDS \\
\hline Images & $\bullet$ & $\bullet$ & $\bullet$ & $\bullet$ \\
\hline Audio & $\bullet$ & $\bullet$ & $\bullet$ & $\bullet$ \\
\hline Video & $\bullet$ & $\bullet$ & $\bullet$ & $\bullet$ \\
\hline Animations & $\bullet$ & $\bullet$ & $\bullet$ & $\bullet$ \\
\hline Java applets & $\bullet$ & $\bullet$ & & \\
\hline \hline Points & 5 & 5 & 4 & 4 \\
\hline
\end{tabular}

Another functional requirement is a development of tests and exercises (Tab.8). Well-designed tests could essentially improve educational process. Authors can typically use single choice, multi choice, assigning or filling exercises. After each finished lesson a short test is usually recommended. It is necessary to mention, that especially tools CourseLab and myUdutu offer rich and intuitive templates for tests development.

Table 8 Tests and exercises

\begin{tabular}{|c|c|c|c|c|}
\hline & CourseLab & eXe & myUdutu & LCDS \\
\hline $\begin{array}{c}\text { Single } \\
\text { choice }\end{array}$ & $\bullet$ & $\bullet$ & $\bullet$ & $\bullet$ \\
\hline $\begin{array}{c}\text { Multi } \\
\text { choice }\end{array}$ & $\bullet$ & $\bullet$ & $\bullet$ & $\bullet$ \\
\hline Ordering & $\bullet$ & & $\bullet$ & \\
\hline Assigning & $\bullet$ & & $\bullet$ & $\bullet$ \\
\hline Filling & $\bullet$ & $\bullet$ & & \\
\hline \hline Points & 5 & 3 & 4 & 3 \\
\hline
\end{tabular}

Interactive components and scenarios are the fifth functional requirement to allow knowledge acquiring in interesting form and to enhance attention of students (Tab. 9). The tools myUdutu and LCDS offer a lot of intuitive templates with interactive elements and multimedia scenarios. Special attention in this area belongs to CourseLab as it is the only object-oriented tool that allows skilled authors to develop quite complex multimedia animations. On the other hand, authoring tool eXe is behind in this area. 
Table 9 Interactivity and scenarios

\begin{tabular}{|c|c|c|c|c|}
\hline & CourseLab & eXe & myUdutu & LCDS \\
\hline $\begin{array}{c}\text { Interactive } \\
\text { components }\end{array}$ & $\bullet$ & & $\bullet$ & $\bullet$ \\
\hline Scenarios & $\bullet$ & & $\bullet$ & $\bullet$ \\
\hline $\begin{array}{c}\text { Advanced } \\
\text { animations }\end{array}$ & $\bullet$ & & & \\
\hline \hline Points & 3 & 0 & 2 & 2 \\
\hline
\end{tabular}

Last functional requirement are special functions (Tab. 10). Only authoring tool eXe offers Slovak localization rated by 0.2 points. On the other hand, myUdutu provides a good-class glossary and LCDS allows full-text searching, both rated by 1 point.
Table 10 Special functions

\begin{tabular}{|c|c|c|c|c|}
\hline & CourseLab & eXe & myUdutu & LCDS \\
\hline $\begin{array}{c}\text { Slovak } \\
\text { localization }\end{array}$ & & $\bullet$ & & \\
\hline Glossary & & & $\bullet$ & $\bullet$ \\
\hline Searching & & & & $\bullet$ \\
\hline \hline Points & 0 & 0.2 & 1 & 2 \\
\hline
\end{tabular}

Finally, summary of requirements is shown in Tab. 11. Maximal values that are possible to get for specific benchmarking requirements are presented in column Max.

In Tab. 12, fractions of gained points and maximal values for each requirement or parameter are listed.

Table 11 Summary of requirements

\begin{tabular}{|c|c|c|c|c|c|c|}
\hline & Parameter & CourseLab & eXe & myUdutu & LCDS & Max \\
\hline A & $\begin{array}{c}\text { Software platforms } \\
\text { support }\end{array}$ & 2 & 3 & 3 & 2 & $\mathbf{3}$ \\
\hline B & Course export & 2 & 2 & 2 & 2.5 & $\mathbf{2 . 5}$ \\
\hline C & Standards support & 3 & 1,5 & 2 & 1 & $\mathbf{3 , 5}$ \\
\hline D & $\begin{array}{c}\text { Web browsers } \\
\text { optimization }\end{array}$ & 2 & 5 & 5 & 1 & $\mathbf{5}$ \\
\hline E & $\begin{array}{c}\text { Course design, } \\
\text { documents import }\end{array}$ & 2 & 0 & 4 & 1 & $\mathbf{4}$ \\
\hline F & Text editing & 2 & 3 & 3 & 2 & $\mathbf{4}$ \\
\hline G & Multimedia support & 5 & 5 & 4 & 4 & $\mathbf{5}$ \\
\hline H & Tests, exercises & 5 & 3 & 4 & 3 & $\mathbf{5}$ \\
\hline I & Interactivity, scenarios & 3 & 0 & 2 & 2 & $\mathbf{3}$ \\
\hline J & Special functions & 0 & 0.2 & 1 & 2 & $\mathbf{2 . 2}$ \\
\hline
\end{tabular}

Table 12 Fractional values (p)

\begin{tabular}{|c|c|c|c|c|}
\hline & CourseLab & eXe & myUdutu & LCDS \\
\hline A & 0,66667 & 1 & 1 & 0,66667 \\
\hline B & 0,8 & 0,8 & 0,8 & 1 \\
\hline C & 0,85714 & 0,42857 & 0,57143 & 0,28571 \\
\hline D & 0,4 & 1 & 1 & 0,2 \\
\hline E & 0,5 & 0 & 1 & 0,25 \\
\hline F & 0,5 & 0,75 & 0,75 & 0,5 \\
\hline G & 1 & 1 & 0,8 & 0,8 \\
\hline H & 1 & 0,6 & 0,8 & 0,6 \\
\hline I & 1 & 0 & 0,66667 & 0,66667 \\
\hline J & 0 & 0,09091 & 0,45455 & 0,90909 \\
\hline
\end{tabular}

In Tab. 13, weights of parameters are calculated according to importance of each parameter. For example, if parameter $\mathrm{B}$ is more important than parameter $\mathrm{A}$, then parameter B obtains more points from maximum 10 points, in our case, 8 points for parameter B and 2 points for parameter A. Weight of parameter is calculated as division of sum for particular parameter and overall sum, e.g., weight of parameter $A$ is equal to $0.02222=10 / 450$. Calculated priority order of parameters is shown in table right column and certainly is very subjective.

Benchmarking rating of each parameter in Tab. 14 is calculated by multiplication of fractional values (p) from Table 12 and parameters weights (w) from Table 13. Final benchmarking results are shown in Tab. 15.

Table 13 Calculation of parameters weights (w)

\begin{tabular}{|c|c|c|c|c|c|c|c|c|c|c|c|c|c|}
\hline & A & B & C & D & E & F & G & H & I & J & $\sum$ & Weight & Priority \\
\hline A & - & 2 & 1 & 1 & 2 & 1 & 1 & 1 & 0 & 1 & 10 & 0,02222 & 10. \\
\hline B & 8 & - & 3 & 2 & 5 & 3 & 3 & 3 & 1 & 2 & 30 & 0,06667 & 9. \\
\hline
\end{tabular}




\begin{tabular}{|c|c|c|c|c|c|c|c|c|c|c|c|c|c|}
\hline $\mathbf{C}$ & 9 & 7 & - & 5 & 6 & 5 & 5 & 6 & 5 & 5 & 53 & 0,11778 & 3. \\
\hline $\mathbf{D}$ & 9 & 8 & 5 & - & 7 & 6 & 6 & 5 & 4 & 5 & 55 & 0,12222 & 2. \\
\hline $\mathbf{E}$ & 8 & 5 & 4 & 3 & - & 5 & 5 & 6 & 4 & 5 & 45 & 0,10000 & 8. \\
\hline $\mathbf{F}$ & 9 & 7 & 5 & 4 & 5 & - & 6 & 6 & 4 & 5 & 51 & 0,11333 & 4. \\
\hline $\mathbf{G}$ & 9 & 7 & 5 & 4 & 5 & 4 & - & 6 & 4 & 5 & 49 & 0,10889 & 6. \\
\hline $\mathbf{H}$ & 9 & 7 & 4 & 5 & 4 & 4 & 4 & - & 4 & 5 & 46 & 0,10222 & 7. \\
\hline I & 10 & 9 & 5 & 6 & 6 & 6 & 6 & 6 & - & 6 & 60 & 0,13333 & 1. \\
\hline J & 9 & 8 & 5 & 5 & 5 & 5 & 5 & 5 & 4 & - & 51 & 0,11333 & 4. \\
\hline & & & & & & & & & & $\sum=$ & 450 & & \\
\end{tabular}

Table 14 Calculation of parameter benchmarking rating

\begin{tabular}{|c|c|c|c|c|}
\hline & CourseLab & eXe & myUdutu & LCDS \\
\hline & $\mathrm{p}^{*} \mathrm{~W}$ & $\mathrm{p}^{*} \mathrm{~W}$ & $\mathrm{p}^{*} \mathrm{~W}$ & $\mathrm{p}^{*} \mathrm{~W}$ \\
\hline $\mathbf{A}$ & 0,01481 & 0,02222 & 0,02222 & 0,01481 \\
\hline $\mathbf{B}$ & 0,05334 & 0,05334 & 0,05334 & 0,06667 \\
\hline $\mathbf{C}$ & 0,10095 & 0,05048 & 0,06730 & 0,03365 \\
\hline $\mathbf{D}$ & 0,04889 & 0,12222 & 0,12222 & 0,02444 \\
\hline $\mathbf{E}$ & 0,05 & 0 & 0,1 & 0,025 \\
\hline $\mathbf{F}$ & 0,05667 & 0,08500 & 0,08500 & 0,05667 \\
\hline $\mathbf{G}$ & 0,10889 & 0,10889 & 0,08711 & 0,08711 \\
\hline $\mathbf{H}$ & 0,10222 & 0,06133 & 0,08178 & 0,06133 \\
\hline $\mathbf{I}$ & 0,13333 & 0 & 0,08889 & 0,08889 \\
\hline $\mathbf{J}$ & 0 & 0,01030 & 0,05151 & 0,10303 \\
\hline$\sum$ & $\mathbf{0 , 6 6 9 1 0}$ & $\mathbf{0 , 5 1 3 7 8}$ & $\mathbf{0 , 7 5 9 3 7}$ & $\mathbf{0 , 5 6 1 6 0}$ \\
\hline
\end{tabular}

Table 15 Final benchmarking results

\begin{tabular}{|c|c|c|}
\hline & Authoring tool & Rating (max. 1.0) \\
\hline 1. & myUdutu & 0,76 \\
\hline $\mathbf{2 .}$ & CourseLab & 0,67 \\
\hline 3. & MS LCDS & 0,56 \\
\hline 4. & eXe & 0,51 \\
\hline
\end{tabular}

\section{EVALUATION OF BENCHMARKING}

It is necessary to mention, that any benchmarking is subjective. Final benchmarking results are essentially affected by selection of parameters that should be conformable with user requirements. In our case, we assume user without any higher technical skills and we are looking for appropriate free authoring tool for multimedia course development. Furthermore, every multimedia project has its own specifications and requirements that directly influence selection of authoring tool. As a consequence, final benchmarking results in Tab. 15 are not so important as actual user requirements and possibilities. In next paragraphs, we will evaluate each authoring tool in terms of its suitability to various types of multimedia projects.

Online authoring tool myUdutu gained highest ranking as it fulfil majority of requirements. Courses produced by this tool are appropriate for wide public due to optimization for all web browsers and professional course design. Moreover, this is only tool that offers free import of PowerPoint presentations and pdf documents. Intuitive templates provide user-friendly development of tests, interactive components and even relatively complex scenarios. Following, also technically less experienced users are able quite simply to develop professional multimedia courses. On the other hand, this tool is not object-oriented one and it does not allowed to produce advanced multimedia projects with sophisticated animations. Moreover, guarantee of online web service could be unsafe for some kind of projects.

Authoring tool CourseLab could get higher ranking if we would select an additional benchmarking parameter regarding advanced multimedia animations. This tool allows realizing complex multimedia projects due to object-oriented development. Although it is suitable for production of standard multimedia courses, preparation of various interactive components can be more difficult than in case of templates oriented tools. Weakness could be a course optimization for only two web browsers.

Major advantage of authoring tool Microsoft LCDS is a simple production of different interactive components 
based on templates and professional course design as well. As a consequence, multimedia course development is rather intuitive and quick. Advantage could be full-text searching and generally, Microsoft warranty and rich experiences in the field of online multimedia courses. Main disadvantage for some users could be a course optimization for only Internet Explorer. Authors should also consider some limitations of text editing and they should verify if provided templates are sufficient for particular multimedia project.

Open-source tool eXe gained lowest ranking due to unprofessional course design and very weak support of interactivity and scenarios. Certainly, technically skilled users are able to overcome mentioned problems and, on the other hand, they appreciate the tool openness, all browsers optimization, rich text editing, Java applets importing and mathematical formulas inserting.

\section{CONCLUSIONS}

Finally, it is important to highlight that a correct implementation of any multimedia project assumes a rigorous analyses of all requirements and following selection of appropriate authoring tool. Presented benchmarking confirmed that also technically less skilled users have available good-class free authoring tools for multimedia courses development. Obviously, number of free tools is essentially lower than amount of commercial authoring tools that provide much additional functionality especially in the area of complex multimedia animations and scenarios.

\section{ACKNOWLEDGMENT}
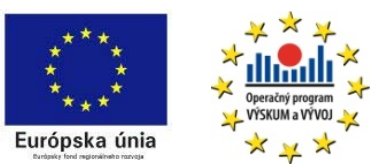

We support research activities in Slovakia. Project is co-financed from EU funds. This paper was developed within the Project "Centrum excelentnosti integrovaného výskumu a využitia progresívnych materiálov a technológií $\mathrm{v}$ oblasti automobilovej elektroniky", ITMS 26220120055.

\section{REFERENCES}

[1] KOCUR, P: Přehled vybraných autorských systémů (Authoring Tools) jako nástrojů pro tvorbu multimediálních on-line e-learningových modulů (kurzů) a multimediálních elektronických učebnic. Plzeň, 2005.

[2] AICC - Aviation Industry CBT Committee, http://www.aicc.org.

[3] IMS Global Learning Consortium, http://www.imsglobal.org/

[4] ADL - Advanced Distributed Learning, http://www.adlnet.gov

[5] Microsoft Learning Content Development System (LCDS), http://www.microsoft.com/learning/en/us/training/lc ds.aspx.
[6] CourseLab, http://www.courselab.com/

[7] eXe - the eLearning XHTML editor, http://exelearning.org/wiki

[8] myUdutu - Online Collaborative Course Authoring, http://www.udutu.com/

[9] NENADÁL, J.: Měření v systémech managementu jakosti, Praha, 2001, ISBN 80-7261-054-6.

[10] GANCHEV, I. - O'DROMA, M. - ANDREEV, R.: Functionality and SCORM-compliancy Evaluation of eLearning Tools, ICALT 2007, Seventh IEEE International Conference on Advanced Learning Technologies, 18-20 July, 2007, pp. 467-469.

[11] KASKALIS, T. - TZIDAMIS, T. - MARGARITIS, K.: Multimedia Authoring Tools: The Quest for an Educational Package, Journal of Educational Technology \& Society, Vol. 10, No. 3, pp. 135-162, 2007.

Received May 23, 2011, accepted September 29, 2011

\section{BIOGRAPHIES}

Peter Košč was born in 1964 in Košice, Slovakia. He received the MSc and $\mathrm{PhD}$ at the Faculty of Electrical Engineering, Technical University of Košice, in 1988 and 1994. His research interests are e-learning technologies and human resources development. He was involved in several EU projects in the area of e-learning technologies and development of Learning Content Management Systems.

Mária Gamcová was born in 1965 in Slovakia. She graduated in 1989 (MSc) with distinction at the Department of Radioelectronics of the Faculty of Electrical Engineering and Informatics at Technical University in Košice. She defended her $\mathrm{PhD}$ in the field of telecommunications in 2005. Since 1991 she has been teaching Electronics basic, Theory of linear circuits and microwave technology subjects at the Department of Electronics and Telecommunications. Her actual scientific research focuses on sensor networks and wireless communications technologies for automobiles e-learning technologies.

Ján Štec was born in 1987 in Slovakia. He received the $\mathrm{MSc}$ at the Faculty of Electrical Engineering and Informatics, Technical University of Košice, in 2011. His research interests are multimedia technologies and authoring tools.

Dušan Kocur was born in 1961 in Košice, Slovakia. He received his Ing. (MSc) and CSc. (PhD) in Radioelectronics from the Faculty of Electrical Engineering, Technical University of Košice, in 1985 and 1990, respectively. He is full professor at the Department of Electronics and Multimedia Communications of his Alma Mater. His research interests are radar signal processing, UWB technologies, signal processing for wireless communications and e-learning technologies. 